This is the author's version of a work that was published in the following source:

Salah, F.; Flath, C. M.; Schuller, A.; Will, C.; Weinhardt, C. (2017).

Morphological analysis of energy services: Paving the way to quality differentiation in the power sector .

Energy policy, 106, 614-624. doi:10.1016/j.enpol.2017.03.024

Please note: Copyright is owned by the author(s) and / or the publisher. The commercial use of this copy is not allowed. 


\title{
Morphological analysis of energy services: Paving the way to quality differentiation in the power sector
}

\author{
Florian Salah ${ }^{\mathrm{a}, *}$, Christian Will ${ }^{\mathrm{a}}$, Alexander Schuller ${ }^{\mathrm{b}}$, Christoph M. Flath ${ }^{\mathrm{c}}$, Christof \\ Weinhardt ${ }^{\mathrm{a}}$ \\ ${ }^{a}$ Karlsruhe Institute of Technology, Kaiserstr. 12, 76131 Karlsruhe, Germany \\ ${ }^{b}$ FZI - Research Center for Information Technology, Haid-und-Neu-Str. 10-14, 76131 Karlsruhe, Germany \\ ${ }^{c}$ University of Würzburg, Josef-Stangl-Platz 2, 97070 Würzburg, Germany
}

\begin{abstract}
The activation of the still predominantly passive demand side is necessary to further guarantee a stable power system in the short term and ensure capacity adequacy in the long run. A system with a high share of generators with nearly no marginal costs requires new services that facilitate transmitting the right economic signals to the system stakeholders. To this end we refine the notion of energy services and propose a framework to systematically design quality differentiated energy services for consumers. This approach facilitates a value-based economic assessment of energy services that deviates from the marginal-cost-paradigm. We further illustrate pricing options for these new energy service products and outline infrastructural needs and additional use case-specific product properties. Moreover, we discuss how the morphological approach can be formalised using a mathematical programming formulation and introduce a complexity measure that facilitates assessing potential adoption obstacles for end consumers. Additionally, we illustrate the practical applicability of these findings by using a prototypical implementation of a decision support system. To foster differentiated energy services, we recommend a more lenient regulatory regime lowering the barriers for new market entrants.
\end{abstract}

Keywords: Product differentiation, Energy service, Morphological analysis, Service design, Decision support

\footnotetext{
*Corresponding Author

Email address: florian.salah@kit.edu (Florian Salah)
} 


\section{Introduction}

Currently, system stability is primarily ensured by supply side operations, in particular load balancing through conventional generators and system reserves. This traditional control approach may become increasingly unreliable due to uncertainty of intermittent renewable energy sources and decommissioning of conventional power plants. The increase of intermittent renewable energy sources on the supply side effectively decreases the share of controllable elements in the power system. The arising imbalance can be compensated through activation of the so far mainly passive demand side. To this end, appropriate economic incentives need to be designed.

However, these economic incentives need to be embedded in attractive service offerings corresponding to the individual application scenarios for different customer groups. This in turn requires the development of new products and services and considerations about the appropriate market environment. Fundamentally, these service offerings need to pave the way towards a value-oriented pricing paradigm instead of relying on the current marginalcost-based assessment for the value of electricity. Marginal-cost-pricing will fail in the longrun if power systems are increasingly governed by zero-marginal-cost generation with high output volatility.

Our research objective is to characterise the corresponding energy service concept and to provide a structured approach to design energy service products for end customers under consideration of the key product characteristics. To this end we follow Zwicky (1967) and present a structured morphological approach to explore design dimensions for energy services encompassing the four categories of risk, pricing options, infrastructural requirements, and product properties.

First, we further specify what an energy service is in the context of this work and build on and adapt existing definitions of this term in Section 2. Additionally, we consider previous work regarding product differentiation in the electricity sector and more general in the service sector. From these foundations we derive the methodology built on Zwickys framework in Section 3. Section 4 presents the morphological box for energy services while Section 5 
elaborates on interdependencies between design options and the complexity related to energy service features. Furthermore, we illustrate the usage of the box by characterising realworld service configurations and a prototypical decision support system for service designers. Section 6 concludes and discusses policy implications for regulators to support the process of advancing energy services.

\section{Related work}

This section revisits existing definitions of energy services and looks into general service design properties to guide our morphological approach for service innovation in the energy domain.

\subsection{Energy services}

The term energy service has different meanings in literature. These meanings can be classified into three main streams: Understanding the classic business of utilities as a service, planning, installation and financing of small power plants (e.g., photovoltaic power plants) and services enabled by the use of energy.

Hill (1977, p. 317) defines a good as "a physical object which is appropriable and, therefore, transferable between economic units". In contrast, "one economic unit performing some activity for the benefit of another" and thereby changing the condition of a person or a good is the idea of a service (Hill, 1977, p. 318). In line with this reasoning, Kloubert (2000) identifies two components in the classic core offering of utilities: The energy carrier (e.g., coal, gas) itself is a typical good. Transmitting this good in a possibly modified form to customers adds the characteristics of a service. Utility companies extend the so-called dual core offering by auxiliary services such as metering, consumption optimisation, and emergency services.

Following Vine (2005), energy services consist of developing, installing and funding multiyear projects that enhance the energy efficiency or load reduction of customer facilities. Especially in the US, the literature employs the term "ESCO" (energy service company) to refer to this definition (Dayton et al., 1998; Goldman et al., 2005; Satchwell, 2010; Vine et al., 
1999). This is in line with the notion of energy services as defined by Rosmanith et al. (2007) and the EU directive 2006/32/EC: An energy service is "the physical benefit, utility or good derived from a combination of energy with energy efficient technology and/or with action, which may include the operations, maintenance and control necessary to deliver the service, which is delivered on the basis of a contract and in normal circumstances has proven to lead to verifiable and measurable or estimable energy efficiency improvement and/or primary energy savings." "1

In contrast to Vine's and Hill's understanding, Sorrell (2007) focuses on the service itself: "Energy service contracting involves the outsourcing of one or more energy-related services to a third party". This includes e.g., basic services like hot water supply or more sophisticated service offerings, such as illumination levels, room temperatures etc. Seizing the three-stage-framework of offering a service due to Kloubert (2000), Sorrell adds the result stage - transforming energy to something valuable for the customer — to the first two stages. These consist of (1) setting up infrastructures and procuring primary energy carriers and (2) producing and transmitting the energy, which is the base for the following considerations.

Building on Sorrell's definition we understand energy services as services that are facilitated by energy, in particular for energy-intensive applications, offered on the mass market. This notion introduces a new facet that facilitates to provide a value-based assessment of the utilisation of energy that is differentiated by the end-use application. In turn this enables new options to harness demand side flexibility potentials which are of great importance in future energy systems with large shares of intermittent generation sources (IEA, 2014).

\subsection{Product differentiation in the electricity sector}

Electricity is typically considered as a homogeneous good. Therefore, product differentiation has mainly concentrated on dynamic pricing so far (Tan and Varaiya, 1993). Real-time pricing (RTP) and other variable pricing schemes are well-known and studied examples Albadi and El-Saadany, 2008; Woo et al., 2014; Borenstein, 2005). Direct load control (DLC)

\footnotetext{
${ }^{1}$ Article 3(e), Directive 2006/32/EC of the European Parliament and of the council.
} 
is another way to manage the balance of demand and supply. In DLC programs utilities offer incentives to customers in exchange for accepting pre-specified curtailment options (Albadi and El-Saadany, 2008). Further work concentrates on differentiation of electricity with regard to conventional attributes like the generation source (Kaenzig et al., 2013). Recently, the willingness to pay for green generation options has been extensively studied (Roe et al. 2001; Borchers et al., 2007; Yoo and Kwak, 2009; Hansla et al., 2008). Depending on the scenario, most studies find a higher willingness to pay for electricity from renewable sources.

Other network-based industries, e.g., telecommunication, evolved in a comparable way (Rjnaldi, 2004). Deregulation of the telecommunication market induced competition which forced the development of innovative and heterogeneous products to account for individual customer needs (Kenyon and Cheliotis, 2001). In analogy to that, product differentiation in the electricity sector should not only concentrate on pricing and power quality but also on different customer usage scenarios. The ongoing implementation of smart grids forms the technical basis for this development (Woo et al., 2014). This way, the (physically) homogeneous good electricity becomes a differentiable transaction object in economic terms (Weinhardt et al., 2003).

\subsection{Product differentiation in the service sector}

Since the notion of energy services builds on the service concept, differentiation can in particular be attained by a variation of service quality attributes. Service quality has been subject to extensive research mainly building on top of quality indicators established in the SERVQUAL framework (Parasuraman et al., 1988). This framework focuses on "traditional" services performed by humans e.g., in stores, banks, or other businesses. The relevant service quality dimensions include the perception of tangibles, reliability, responsiveness, assurance, and empathy. Some of these concepts are also applicable to energy services, but have a different facet in their implementation. Tangibles for example are not as relevant or cannot be influenced, as well as empathy, and to some extent assurance, since the service is delivered through a device or appliance according to clearly defined technical specifications. 
Parasuraman et al. (2005) have also put forward an important modification of the SERVQUAL concept to reflect the rise of electronic or e-services. The E-S-QUAL framework incorporates insights from numerous studies employing the Theory of Planned Behavior (TPB) and the Technology Acceptance Model (TAM). Its objective is to measure the "extent to which a website facilitates efficient and effective shopping, purchasing, and delivery." The general attitude towards the technological means that deliver a service can also be of importance for the energy services depicted later, since they too rely on technical interfaces. However, the focus of our work is to first define and characterise differentiation concepts, rather than assessing a particular implementation of one. The following main indicators employed in E-S-QUAL measure the quality of a service: reliability (correct technical function of a site), responsiveness (low latency and fast customer support), access (easy and timely), flexibility (choice of payment, shipping etc; rather referred to the delivery process), ease of navigation, efficiency (simple and effective usage design), assurance/trust (reputation of the site), security/privacy (data security level of the provider), price knowledge (price determination transparency during the purchasing process), site aesthetics, customisation/personalisation (user profiles).

Several of these indicators are directly applicable to energy service evaluation, in particular assurance/trust and security/privacy. Others like reliability and responsiveness can be adapted in a straightforward manner: The reliability of an energy service is intrinsically connected to the appliance that provides the service. Its reliability will typically be governed by the availability of energy to the appliance. The responsiveness dimension depends on user service quality expectations and behavior - e.g., frequency and required immediateness of service delivery. This plays a crucial role in Section 4 .

Service access, flexibility and efficiency require a nuanced interpretation in the energy domain: Access, for instance, may be restricted due to technical constraints (e.g., insufficient fuse capacity), or because the respective infrastructure (e.g., smart meter) is unavailable. Flexibility is employed differently in this work (see Section 4.1). The efficiency of an energy service is the energy consumption relative to a similar service. Naturally, most of the other dimensions also play a role for energy services when they are marketed or controlled. 
Furthermore, future energy services can be attributed to the e-service domain as well. This is because such novel services are enabled by the smart grid ICT layer extending standard grids. Consequently, the e-service dimensions apply as well and do not require a specific domain adaptation.

\section{Methodology}

We seek to approach energy service design in a methodical fashion. To this end, we tie our research to the economics literature on quality differentiated products and the morphological design theory established by Zwicky (1948). In a nutshell, the economic framing illustrates the fundamental potential of energy service differentiation and thus establishes the answers to the "why" energy service innovation is required. Conversely, the morphological theory provides a structured approach for design processes and thus facilitates a better understanding of "how" service innovation can be managed in an effective manner.

\subsection{Economics of quality differentiation}

At the economic core of our problem stands the idea of companies exercising price discrimination between customers to extract profit. We will provide a quick overview on the subject matter and refer for an in-depth treatise to the extensive industrial organisation literature in this field (e.g., Varian, 1989; Tirole, 1988). The standard definition of Pigouvian price discrimination considers perfect price discrimination (first-degree), direct price discrimination based on observable customer characteristics (third-degree), and indirect price discrimination based on customer self-selection (second-degree). Highly customised energy services facilitate second-degree price discrimination 2 Product differentiation through versioning is the key building block for this approach. To proceed, it is helpful to establish additional concepts:

\footnotetext{
${ }^{2}$ Naturally, third-degree price discrimination also applies when targeting clearly identifiable segments such as industrial customers or residential customers with special equipment such as PV generation, electric vehicles or micro-CHP heating.
} 
- Differentiated products: The products in an industry are differentiated if customers consider them as (close but) imperfect substitutes.

- Vertically differentiated products: A vertically differentiated product space is characterised by a common preference ordering of the product offerings across customers ${ }^{3}$

- Horizontally differentiated products: In a horizontally differentiated product space the consumers do not agree on the preference ordering. 4

In the following, we explore options of establishing quality discrimination in electricity provision through distinct energy service offerings. As we will see, these differentiation options allow for both vertical (e.g., reliability level) and horizontal differentiation (time-ofuse brackets) of electricity products.

Product differentiation in power systems. Electricity is a fundamentally homogeneous good characterised by relevant physical properties (e.g., voltage or current). After all, it was this standardisation that paved the way for the electrical age. Consequently, there is no such thing as differentiated electricity. However, product differentiation is enabled by wrapping the homogeneous commodity in a service offering that is marketing "energy services" instead of a commodity. This reflects the simple observation that "an end use device uses electric energy to provide a service to the customer" (Schweppe et al. 1989). It is this service which customers ultimately benefit from and which explains their willingness to pay. This differentiated view on electricity consumption paves the way for different forms of product differentiation through establishment of various quality of service classes, e.g., time of service delivery or reliability guarantees.

A stylised example. The canonical example for product differentiation of energy services is due to Chao and Wilson (1987) and reflects a reliability-price trade-off. We present a

\footnotetext{
${ }^{3}$ If all products sell for the same price, all consumers choose the same product (the one with the highest quality).

${ }^{4}$ If all products are sold at the same price the optimal choice depends on the particular consumer.
} 


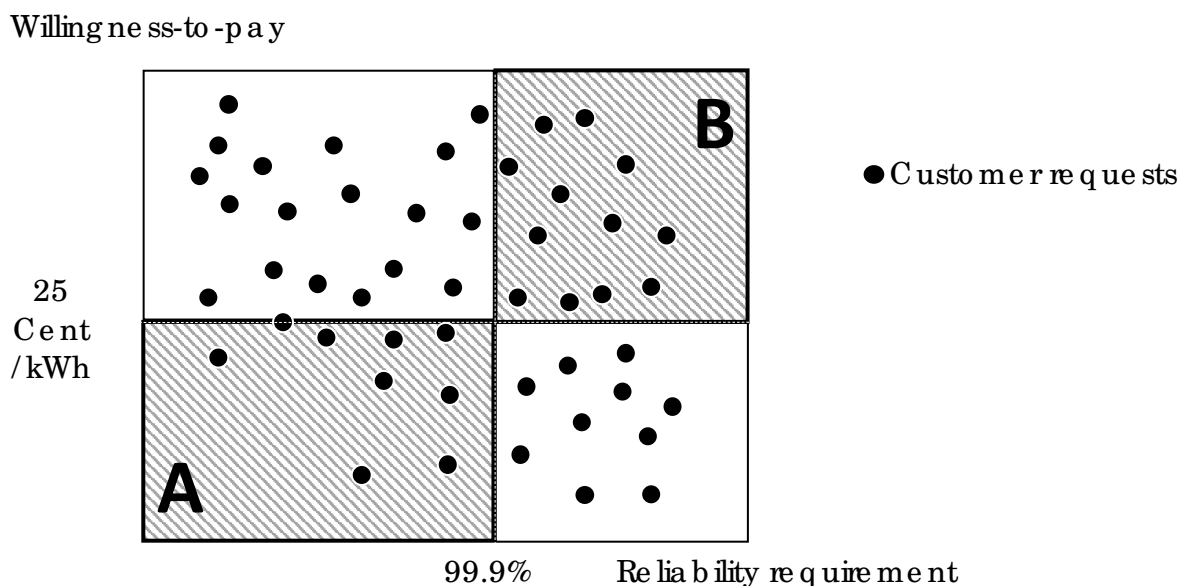

Figure 1: A stylised model of energy service differentation

simplified version to illustrate the potential of increased efficiency by virtue of differentiated energy services. Assume that there are just two dimensions that customers care about when selecting an energy service offering - price and service reliability. The customer population is heterogeneous with respect to their quality requirements and their willingness-to-pay. Such a stylised market is illustrated in Figure 1. Often, an energy provider may offer a single homogeneous and hence non-differentiated product to this customer population. In the Figure this example product is shown with a $99.9 \%$ reliability level at a price of 25 cent/kWh. Only the customers in the top-left quadrant will consume this service. Customers in the right quadrants require a higher service quality, whereas customers in the bottom quadrants are priced out of the market.

While this may be the profit-maximising single service offering for the provider, it is obvious that it simultaneously leads to inefficient over- and underprovision of quality. Consequently, differentiated service offerings (e.g., high reliability-high price, low reliability-low price) can increase allocative efficiency. The customer pools that the supplier potentially reaches are labelled $A$ and $B$ - the former group is interested in less costly offers with lower reliability guarantees, the latter group is willing to pay a premium for higher reliability. 


\subsection{Morphological analysis}

The morphological approach is a creativity technique for developing different designs for a certain artifact. It facilitates both surveying the problem area as well as the generation of concrete solution approaches. Morphological analysis is due to Zwicky who summarised the approach as a structured analysis of systems (Zwicky, 1948). While historically rooted in engineering and the design of physical products, the method has also spread into the service design domain. For example, Lay et al. (2009) apply morphological analysis to explore service-oriented business models in the B2B context. Similarly, Aurich et al. (2010) develop service offerings for industrial goods. Recent contributions use the technique to develop service offerings for electric vehicle ecosystems (Kley et al., 2011; Stryja et al., 2015).

To this end, one compiles a comprehensive list of design dimensions (parameters) describing generic aspects of the analysed system. Subsequently, one needs to identify concrete design options (elements) for each parameter. For illustration, consider the following stylised example: When designing an office chair we can imagine the following parameters upholstery, frame, height adjustment, and backrest. For the upholstery we can choose from the elements leather, cotton, or plastic. The design elements for the frame are column, tripod, or quadpod. There may be no height adjustment, one with discrete levels, or a continuous adjustment. Finally, the back rest can be absent, fixed, retractable. This information is arranged in matrix form — the so-called morphological box (Zwicky, 1967) — with parameters as rows and and elements as columns. By selecting one element per parameter (one matrix cell per row) one can recombine design options to create distinct solution instances. Finally, one needs to evaluate the individual solution candidates to determine the final choice(s).

Note that the option space exhibits combinatorial growth in parameters and elements with the gross number of solution options obtaining as $\prod_{p \in P}|E(p)|$. In the example we have $3^{4}=81$ design options for the chair. To limit this solution space explosion one should search for interdependencies between different elements from different parameters which facilitate reducing the solution space. In the chair example a reasonable assumption is that height adjustment is only available for the case of a column frame. This reduces the number of possible solutions to 45 . This observation relates to the two stage product line selection 


\begin{tabular}{|c|c|c|c|c|c|}
\hline & Parameter & \multicolumn{4}{|c|}{ Design Elements } \\
\hline \multirow{3}{*}{ 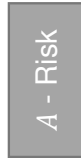 } & Quantity & None & \multicolumn{2}{|c|}{ Limited (partial execution) } & Unlimited \\
\hline & Interruption & None & \multicolumn{2}{|c|}{ Limited (frequency, duration) } & Unlimited \\
\hline & Time of delivery & None & \multicolumn{2}{|c|}{ Limited (deadline) } & Unlimited \\
\hline \multirow{5}{*}{$\begin{array}{l}\frac{0}{2} \\
\frac{2}{0} \\
\frac{0}{2} \\
1 \\
\infty \\
\infty\end{array}$} & Change announcement & None & \multicolumn{2}{|c|}{ With lead time } & Instantaneous \\
\hline & Calculation concept & Flat & \multicolumn{2}{|c|}{ Linear } & Non-linear \\
\hline & Calculation unit & None & \multicolumn{2}{|c|}{ Energy based } & Service purpose based \\
\hline & Temporal differentiation & \multicolumn{3}{|c|}{ Static } & Variable \\
\hline & Spatial differentiation & Uniform & \multicolumn{2}{|c|}{ Roaming } & Nodal \\
\hline \multirow{3}{*}{ 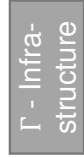 } & Metering & None & \multirow{2}{*}{\multicolumn{2}{|c|}{\begin{tabular}{l||} 
Cumulative \\
Unidirectional
\end{tabular}}} & Continuous \\
\hline & Communication & None & & & Bidirectional \\
\hline & Automation & None & Timer switch & Thresho & Bid agent \\
\hline \multirow{3}{*}{ 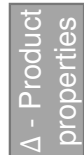 } & Energy source & None & \multicolumn{2}{|c|}{ Energy balance } & Power balance \\
\hline & Power profile & Fully fixed & \multicolumn{2}{|c|}{ Energy fixed } & Fully variable \\
\hline & Power quality & \multicolumn{2}{|c|}{ None } & & Yes \\
\hline
\end{tabular}

Figure 2: Overview of the morphological design options

problem where in the first stage infeasible configurations and dominant features are removed to improve the performance of the subsequent optimisation (Schön, 2010).

\section{Results: A morphological box for Smart Grid services}

In the past, product differentiation in the energy service sector was somewhat neglected due to both a lack of need as well as insufficient technical prerequisites. In the following we develop a morphological box for designing differentiated energy service offerings (see Figure 21. The morphological approach facilitates a more systematic identification of design options for transaction objects in future retail energy services. We group design parameters into four categories — risk, pricing, infrastructure, and product properties. Similar to the approach described by Kley et al. (2011), we effectively obtain four distinct morphological boxes mapping different service characteristics. We further describe these individual boxes and subsequently explore interdependencies between them. 


\subsection{Risk parameters}

The design elements in the first category enable the service provider to reduce, interrupt, or shift the amount of delivered energy services and therefore transfer the respective risks to the customer. Reducing the up-time requirement for specific energy services potentially reduces overall system costs by increasing demand side flexibility. In practice, an unlimited risk is unusual because it can result in a complete execution stop. A reasonable service offering should therefore usually include any type of risk limitation.

Risk in quantity addresses the paradigm of load curtailment. If the risk is limited, it results in a partial execution of the energy service. Similarly, the service provider could interrupt an already started energy service in a limited manner in terms of frequency and duration of the interruption occurrences. For instance in BMW's ChargeForward program5 customers receive up to $\$ 1,540$ per year if they allow interruptions of their charging processes for up to one hour. To account for the load shifting paradigm that directly addresses the volatile character of renewable energy generation, an energy service can be uncertain about its time of delivery. Service providers can guarantee their consumers to fulfill the energy service until a specified deadline instead of immediately executing the service. In accordance with Chao and Wilson (1987) the three risk parameters are closely related as they converge in their extremes: Reducing the quantity to the minimum is equal to an unlimited interruption or shift in time of delivery.

\subsection{Pricing parameters}

The second group of parameters addresses well-known differentiation features for current standard electricity products and their design elements for the energy service concept. Prices of energy services can be uncertain depending on the employed pricing concept. Therefore, besides having no change announcements, service providers can announce changes with a predefined lead time or, in the most complex case, as real-time prices in the short-term or potentially even instantaneous.

\footnotetext{
$\sqrt[5]{\text { http: //content.bmwusa.com/bmwi_pge/index.html }}$
} 
Beside price changes, the calculation concept defines how an energy service is assessed in economic terms. The design elements included are flat, linear and non-linear price calculation concepts. The calculation concept refers in particular to every additional or marginal unit of a service. In this case a flat concept imposes a fixed fee (again disregarding the variable usage) that is only limited by the technical line limits to supply the service device and the ability to actually use the energy service. Every individual can only consume a certain amount of a service since the outside options or other requirements of daily life usually oppose its continuous and unlimited use. Nevertheless, since energy has to be produced, this concept is diminishing energy efficiency efforts and will most likely only play a role when excess renewable supply is available. Linear calculation concepts relate to the price per unit consumed and are well-known from traditional electricity rates. Finally, non-linear pricing can address e.g., shortage situations by imposing non-constant marginal costs of service provision. Thereby higher usage intensity (e.g., fast EV charging - $20 \mathrm{kWh}$ in 30 minutes) results in higher service fees than lower usage intensity (slow charging - $20 \mathrm{kWh}$ in 3 hours), independent of the total amount.

As mentioned before, energy services can in particular be differentiated from "traditional" energy provision by virtue of the calculation unit. Thereby, usage payments are no longer based on energy consumption (i.e., kWh) but rather a service purpose-based metric. For electric vehicles, this is, e.g., the usage time or the distance driven. For an air-conditioning service, imagine some service level related to lighting and HVAC performance in an office building. This type of contracting will only be plausible if a service provider installs the service equipment, e.g., a car-sharing operator (LeVine et al., 2014) or an energy service company offering performance contracting (Davis, 2012). This way device efficiency is not a user decision and the service provider can appropriately calculate the business case ${ }^{6}$

Further differentiation parameters can be temporal and spatial differentiation. Prices that have no temporal differentiation are static and do not depend on the time of service delivery. For variable prices, the underlying price menu may be static (time-of-use pricing)

\footnotetext{
${ }^{6}$ We thank an anonymous reviewer for pointing out this critical qualification.
} 
or dynamic (RTP). This is reflected by the corresponding choice of the change announcement parameter. Spatial differentiation captures that different regions can have specific demand and supply features or network limitations which need to be accounted for in the price, as is currently discussed in the form of nodal pricing schemes. In contrast to this regional differentiation, roaming allows customers to use a service at predefined locations for the same (roaming) price. Finally, the most straightforward design element is a uniform price for the energy service.

\subsection{Infrastructure parameters}

Novel price and risk elements in a smart grid service offering will often entail corresponding infrastructure requirements, which in turn may become part of the service bundle themselves. These will primarily include metering, communication, and control devices which are supplied by service providers to their contracted customers. This is analogous to the telecommunication sector where cell phones, routers, or modems are often provided for the duration of the contract.

Concerning metering equipment, simple service offerings may be realised using legacy Ferraris meters which facilitate only cumulative meter readings. A first extension of metering capabilities was historically established using dual meters for different time periods (e.g., night vs day) or usage classes (e.g., interruptible vs non-interruptible). Additional measurement of peak power is widely used for large industrial customers to penalise power spikes. The recent introduction of smart meters allows quasi-continuous metering with arbitrary granularity. Still, in most commercial realisations so far suppliers opt for 15 minute metering intervals.

Historically, meters are offline without any continuous connection to suppliers. However, communication capabilities can augment the metering infrastructure for novel service approaches. Unidirectional communication channels allow service providers to push price updates to customers. Going one step further, bidirectional communication enables customers to actively communicate with the service provider. These customer messages may specify current availability requirements or transmit market orders. 
Finally, customers may install device automation to improve the interaction with novel service offerings. This way automation can help reduce the perceived complexity of these services. Automation options range from simple timed or threshold-based switches (e.g., maximum payments) to pro-active bid agents adapting to observed and predicted user behavior.

\subsection{Product property parameters}

This group of characteristics introduces specific product category parameters. Following our guiding example of services for electric loads, candidate parameters include the energy source (primary energy), the possibility to alter the power profile, and power quality features.

Currently, electricity is mostly differentiated for marketing purposes by the primary energy source that is converted to electricity in the respective plant type. Utilities hereby guarantee the energy balance from a specific energy source for the demand of the customer. This is one of the two design options that emphasise this product property. Well-known examples for differentiation by energy source are green energy products. The second design option enhances this idea by guaranteeing the power balance with a specific energy source. This incorporates a more direct coupling of the energy service with the current availability of electricity from a specific type of generator. In general, the energy source parameter is added to an energy service by explicitly defining a specific power plant (e.g., wind turbine) or a group of power plants that virtually supplies the energy service in either of the above mentioned shapes. As a consequence this can imply an increased risk of service availability if the energy source is unavailable.

The second parameter contains the ability to alter the power profile. We follow the taxonomy of Petersen et al. (2013) and establish design elements in line with their notion of bakery, batteries, and buckets. The bakery is representative for appliances with a fully fixed power profile. Batteries allow an alteration of the (energy fixed) power profile as long as a target energy level is eventually met. An EV charging service is a perfect match for this group. Fully variable power profiles characterise the bucket class facilitating any load shape and any total energy amount. An example for this design element are heat pumps, 
relaxing not only the power but also the energy constraint in the given time frame. Ideally, the service provider can perform these power profile alterations without affecting the energy service delivered by the appliances.

The final, more technical parameter is power quality. This refers to physical characteristics of electrical power which particularly addresses the needs of commercial and industrial customers. To allow for a general classification this characteristic has binary design elements. For instance, customers could require a guaranteed voltage interval for their energy service, that can be assured by voltage regulated distribution transformers. Or the customer's electrical consumers generate an abnormal amount of reactive power that needs to be compensated by the service provider to support local grids.

\section{Discussion: Use cases for the morphological box}

Since its theoretical solution space is rather big we introduce possibilities to assist future product designers. After introducing a formalisation needed for the consecutive steps, we discuss interdependencies between design elements in Section 5.1 and present a way to describe them mathematically. With the creation of diversified products, complexity for the end consumers becomes an important topic. In Section 5.2 we discuss product complexity and introduce a complexity scoring rule as an extension of the morphological box. Finally, we illustrate the functionality of our proposed morphological box by mapping exemplary energy services to it (Section 5.3) as well as presenting a prototypical decision support system for service designers (Section 5.4).

For the following discussions we propose a formalisation of the morphological box introduced in Section 4. As indicated in Figure 2 energy services can be described by instantiating each parameter with a specific design element. For ease of exposition an instantiation of the morphological box can be represented by means of binary matrices

$$
A=\left(\begin{array}{ccc}
\alpha_{1,1} & \cdots & \alpha_{1, n} \\
\vdots & \ddots & \vdots \\
\alpha_{m, 1} & \cdots & \alpha_{m, n}
\end{array}\right), B=(\ldots), \Gamma=(\ldots), \Delta=(\ldots)
$$


Rows reflect design parameters whereas columns represent the corresponding design elements. If a design option is chosen, the respective binary variable is one and all other design option variables associated to the characteristic are zero. Clearly, for any valid configuration we need to verify that all row sums equal exactly one.

\subsection{Interdependencies between design options}

As discussed in Section 4 there are interdependencies between specific sets of design options. Determining those is key to increase computational efficiency of the product design problem. Therefore, we present a way of handling their occurrences to simplify the process of designing energy services by reducing the theoretical solution space (compare Section 3). Our intention is not to present a complete enumeration of interdependencies but rather to show that mathematical expressions can describe invalid combinations of design options based on illustrative examples.

Most interdependencies exist between either risk $(A)$ or pricing $(B)$ parameters and infrastructure $(\Gamma)$ parameters. If for example one designs an energy service including temporal differentiation with variable rate periods, necessary metering equipment needs to be considered: Evidently, such a rate scheme will require continuous metering for correct billing. This is the simplest form of interdependency and can be formulated as follows:

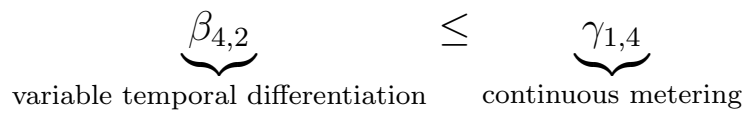

The inequality formulation provides the flexibility to choose non-necessary infrastructure e.g., to preemptively install sophisticated metering for possible future usage.

In the design phase, it is also possible to formulate more complex relations. For example, any type of risk limitation requires interactions between the service provider and the customer. Depending on the use case the customer's willingness to take risks might change, which he or she should communicate to the service provider. Vice versa, during service delivery the provider needs to inform an appliance about when to start, pause or stop. In 
this case the infrastructure has to support bidirectional communication:

$$
\underbrace{\max \left(\alpha_{1,2}, \alpha_{2,2}, \alpha_{3,2}\right)}_{\text {limited risk of any } A \text {-parameter }} \leq \underbrace{\gamma_{2,3}}_{\text {bidirectional communication }}
$$

Note that for unlimited risk unidirectional communication is sufficient as the service provider only has to signal service interruptions to the consumer without confirmation from the customer side. Following Equation 3 this can be expressed as follows:

$$
\underbrace{\max \left(\alpha_{1,3}, \alpha_{2,3}, \alpha_{3,3}\right)}_{\text {unlimited risk of any } A \text {-parameter }} \leq \underbrace{\gamma_{2,2}}_{\begin{array}{c}
\text { unidirectional } \\
\text { communication }
\end{array}}+\underbrace{\gamma_{2,3}}_{\begin{array}{c}
\text { bidirectional } \\
\text { communication }
\end{array}}
$$

Lastly there exists a group of interdependencies where one (or more) design elements require the existence of multiple other design elements. If we design an energy service with price changes that either occur with a lead time or even instantaneous, we need to meter its usage properly and of course we need to communicate these changes to the customer. On the other hand tariffs without an explicit change announcement, as in the case of TOU pricing, do not require communication and are therefore excluded in the following constraint:

$$
\underbrace{\beta_{1,2}+\beta_{1,3}}_{\begin{array}{c}
\text { price changes with lead } \\
\text { time or instantaneous }
\end{array}} \leq \min (\underbrace{\gamma_{1,4}}_{\begin{array}{c}
\text { continuous } \\
\text { metering }
\end{array}}, \underbrace{\gamma_{2,2}+\gamma_{2,3}}_{\begin{array}{c}
\text { uni- or bidirectional } \\
\text { communication }
\end{array}})
$$

As illustrated above, most interdependencies of energy service parameters refer to infrastructure. Still, there do exist interdependencies that are not motivated by infrastructural requirements. For instance, determining a specific (renewable) energy source $\delta_{1,3}$ implicates an unlimited interruption risk of the energy service $\alpha_{2,3}$ (compare Section 4.4):

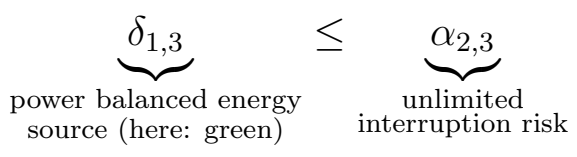

\subsection{Complexity of energy services}

As electricity products are becoming more refined to reflect a changing generation market the complexity of such tariffs is another dimension to be considered. We understand 
complexity as the perceived cognitive strain experienced by (potential) users of such a tariff and the ensuing difficulty of assessing their energy costs, rather than the technical challenge of its implementation (cf. Layer et al., 2016). Chao and Wilson (1987) already observed that "a practical difficulty with spot pricing is that the sample space may be so complex that it would be impossible to implement the spot price in every contingency." Note that this is primarily a contracting dimension and not a risk aversion phenomenon. Consequently, we want to isolate complexity from risk aversion.

To this end, complexity analyses require an assessment of users' satisfaction with a tariff or their purchase behavior. In an early study Goett et al. (2000) discovered small businesses' considerable preference for fixed electricity rates as compared to the more complex TOU pricing, which is in turn preferred to RTP. However, it remains unclear if this preference is really a consequence of cognitive strain or of risk aversion. Dütschke and Paetz (2013) extend this conclusion to private users who are sceptic towards more dynamic tariffs but may reconsider after additional experience with such tariffs. Employing an extensive conjoint analysis, Gerpott and Paukert (2013) meanwhile find the incentive size of smart tariffs to be a more important determinant of users' tariff choice rather than the granularity of temporal differentiation or the lead time. In an extensive empirical study with a sample of 664 participants, Layer et al. (2016) determine increasing dynamics as a fundamental driver of perceived complexity. Communication of subscription rebates in percentages is not found to have a significant impact. Furthermore, the authors find evidence that increased complexity leads to an overestimation of costs. Therefore, it may have a detrimental effect when it comes to choosing such tariffs (cf. Homburg et al., 2014).

In essence, tariff complexity negatively influences customer acceptance of an energy service and this should be considered when applying the morphological box for energy service design (cf. Section 5.4). In the morphological design approach, perceived complexity arises from individual design choices. We surmise that each design option $x_{i, j}$ in the morphological boxes $X \in\{A, B, \Gamma, \Delta\}$ can contribute to the perceived complexity of an energy service. To express these scores we introduce complexity matrices analogous to the design matrices 
from Equation (1):

$$
C^{X}=\left(\begin{array}{ccc}
c_{1,1}^{X} & \cdots & c_{1, n}^{X} \\
\vdots & \ddots & \vdots \\
c_{m, 1}^{X} & \cdots & c_{m, n}^{X}
\end{array}\right) \quad \forall X \in\{A, B, \Gamma, \Delta\}
$$

We suggest ratio scales for the individual weights to facilitate the calculation of an aggregate complexity score of a given energy service. Multiplying a given energy service's morphological matrices for each design category with the corresponding transposed complexity matrices yields a square matrix per design category. The traces of these matrices (sum of diagonal elements) are then the category complexity scores of the given service design configuration. The sum of all the category traces can in turn be interpreted as a measure for the total complexity of a specified energy service:

$$
\text { Complexity(Energy Service) }=\sum_{X} \operatorname{tr}\left(X \cdot\left(C^{X}\right)^{T}\right), \quad \forall X \in\{A, B, \Gamma, \Delta\}
$$

The linear structure of the complexity score is meant primarily for illustration purposes. One can easily imagine a convex function on the total sum or a category score to reflect complexity complementarity. Similarly, the highest individual complexity score can determine the total score.

Clearly, any meaningful evaluation of the complexity score will critically hinge on the measurement of each design option's relative contribution to perceived complexity. Measuring these values will be challenging and potentially subjective. However, for a relative comparison of multiple service configurations under the same complexity premises the ratio scales can be relaxed to interval scales. Eventually, the outlined method can help support service marketing activities by providing the foundation to estimate user response to a tariff created.

\subsection{Exemplary products}

In this section we present four illustrative examples of differentiated energy service products to demonstrate the application and suitability of the morphological approach. 


\subsubsection{Interruptible load}

As a first example we discuss an interruptible electricity service as studied by Oren (2013) that was first implemented by Southern California Edison and several other utilities in the 1980s and has since been further developed (Jazayeri et al., 2005). In such an energy service the utility may interrupt power supply to the customer in response to cost considerations due to unexpected demand spikes or in times of imminent system imbalance. In a particular implementation presented in Oren (2013, Fig. 1) a the service provider compensates a customer for both guaranteeing to be able to interrupt the load and for each time of actually executing the interruption. The number of periods of interruptions is limited to a specific number of times and hours per year.

$$
A=\left(\begin{array}{lll}
1 & 0 & 0 \\
0 & 1 & 0 \\
1 & 0 & 0
\end{array}\right), B=\left(\begin{array}{lll}
1 & 0 & 0 \\
0 & 0 & 1 \\
0 & 1 & 0 \\
1 & 0 & 0 \\
1 & 0 & 0
\end{array}\right), \Gamma=\left(\begin{array}{llll}
0 & 1 & 0 & 0 \\
0 & 0 & 1 & 0 \\
1 & 0 & 0 & 0
\end{array}\right), \Delta=\left(\begin{array}{lll}
1 & 0 & 0 \\
1 & 0 & 0 \\
1 & 0 & 0
\end{array}\right)
$$

The matrices in (9) reflect the formal description of this energy service7. It carries only a limited interruption risk, both in duration and frequency. Pricing is non-linear since a reward for each interruption is added to the traditional linear and static energy rate. There is no temporal or spatial differentiation. Metering can be implemented in the classic cumulative manner, while in practice an additional interruption switch can be installed.

On the one hand the customer can manually responds to a signal of the utility as implemented by the Electric Reliability Council of Texas (Jazayeri et al., 2005). On the other hand the utility can access the switch remotely by means of an unidirectional communication channel as implemented by Minnesota Power (Minnesota Power, 2012). As described in Section 5.1 we suggest to use a bidirectional communication channel to allow customers to dynamically change the risk limit. In contrast to the introductory example both latter

\footnotetext{
${ }^{7}$ Note that zeros shown greyed out in $(9)$ to 12$)$ are preset as these design options are undefined (see Figure 2p.
} 
implementations have a simple linear calculation concept $\left(\beta_{2,2}=1\right)$.

\subsubsection{Real-time electricity pricing}

Conveying scarcity by means of price signals is another option to achieve system-wide power balance. Real-time pricing was first studied by Vickrey (1971) and later applied to electricity in the 1980s (Schweppe et al., 1988). Advocates argue for the long-run efficiency gains of real-time pricing (Borenstein, 2005) compared to static prices even though electricity demand is rather inelastic. Besides the ability to reduce peak demand cost-effectively, economists claim that real-time prices would mitigate market power and reduce price volatility on wholesale markets.

Real-time pricing programs were first introduced in the early 1990s and already counted more than 70 offerings in the 2000s (Barbose et al., 2004). In these - mostly voluntary programs, retail customers must pay prices that vary over short time intervals (e.g., hourly) and are published a day or less in advance by utilities. An advanced and puristic program is offered by the utility Commonwealth Edison (ComEd) in Illinois 8 . ComEd simply passes along the average hourly market price with no mark-up to customers who can thus even partake in negative prices.

$$
A=\left(\begin{array}{lll}
1 & 0 & 0 \\
1 & 0 & 0 \\
1 & 0 & 0
\end{array}\right), B=\left(\begin{array}{lll}
0 & 0 & 1 \\
0 & 1 & 0 \\
0 & 1 & 0 \\
0 & 1 & 0 \\
1 & 0 & 0
\end{array}\right), \Gamma=\left(\begin{array}{llll}
0 & 0 & 0 & 1 \\
0 & 1 & 0 & 0 \\
1 & 0 & 0 & 0
\end{array}\right), \Delta=\left(\begin{array}{lll}
1 & 0 & 0 \\
1 & 0 & 0 \\
1 & 0 & 0
\end{array}\right)
$$

The matrices in $(10)$ shows the formal representation of the morphological box for realtime pricing. Customers do not carry any risk of service quality or availability since pricing aspects address the risk component. In the ComEd example the temporally variable prices are quoted instantaneously. Other programs on the other hand, might have a lead time. Real-time pricing necessitates continuous metering which is one of the biggest obstacles for its

\footnotetext{
8 https://hourlypricing.comed.com/
} 
market launch (Costello, 2004). Additionally, most programs include a form of unidirectional communication to push prices to the metering system.

\subsubsection{Deadline-differentiated pricing for EV charging}

The second service product example captures more complexity and thus explores further options in energy service design. In particular, we consider a deadline differentiated pricing (DDP) approach for an electric vehicle charging service based on Salah and Flath (2016). Under DDP, energy services are differentiated by the latest time of service delivery. To compensate delayed service execution, the service provider offers discounts to consumers. Consumer rebates are increasing in the demand flexibility offered, i.e., a longer accepted delay until completion of the charging job.

$$
A=\left(\begin{array}{lll}
1 & 0 & 0 \\
1 & 0 & 0 \\
0 & 1 & 0
\end{array}\right), B=\left(\begin{array}{lll}
0 & 1 & 0 \\
0 & 1 & 0 \\
0 & 1 & 0 \\
0 & 1 & 0 \\
1 & 0 & 0
\end{array}\right), \Gamma=\left(\begin{array}{llll}
0 & 0 & 0 & 1 \\
0 & 0 & 1 & 0 \\
0 & 0 & 1 & 0
\end{array}\right), \Delta=\left(\begin{array}{lll}
1 & 0 & 0 \\
1 & 0 & 0 \\
1 & 0 & 0
\end{array}\right)
$$

Following the parameters and design elements in Figure 2 the DDP energy service can be formally described by the matrices in (11). This energy service entails no quantity risk, but a limited, in this case deadline-induced, risk for the particular time of delivery. Since to date most electric vehicles reject arbitrary power profiles or even interruptions, the energy service features no interruption risk and a fully fixed power profile $\left(\delta_{2,1}=1\right)$. The service provider announces price changes at latest at the time of arrival at the car park and therefore with lead time. The calculation concept is linear, while the calculation unit will typically be charging energy. Price levels are subject to change depending on grid and generation conditions. A given charging service will typically be location-bound (e.g., a given parking complex) and hence does not facilitate spatial differentiation.

Continuous metering is necessary to facilitate DDP due to possible price changes. Likewise, bidirectional communication will be required to exchange and confirm price information. Besides the physical connection between grid and vehicle, the charging process is auto- 
mated according to the established specifications with service delivery being terminated as soon as the agreed charging level is reached. Finally, the electricity properties will typically exclude both differentiation by energy source and extended power quality requirements.

Bitar and Low (2012), Nayyar et al. (2014) and Chen et al. (2015) present generalised versions of this energy service that abstracts from the EV charging context. In these cases restrictions on interruption $\left(\alpha_{2,2}=1\right)$ and power profile alteration $\left(\delta_{2,3}=1\right)$ of contracted loads are loosened.

\subsubsection{Local energy market}

Unlike regular tariff relationships where suppliers and customers agree on conditions for several transactions, local energy markets are characterised by repeated spot transactions with allocation and prices arising from bids and asks of market participants. Consequently, a sizeable share of system risk is transferred to the demand side - either in the form of price risk (guaranteed delivery may be risky in the presence of price spikes) or quantity risk (limit prices curtail price risk but may lead to non-execution). In the 1980s the seminal work on optimal spot pricing (Schweppe et al., 1981; Schweppe, 1988) conceptualised local energy markets as an advanced form of energy service intermediation. Diverse research projects (e.g., Hammerstrom et al., 2007; Giordano et al., 2011) showcased prototype implementations. A wide-scale adoption of smart grids will create the technological basis for establishing energy marketplaces outside of small-scale experimental settings. Consequently, recent research in energy and computational economics has revisited the design challenges embedded in creating and rolling out such local energy markets (Ketter et al., 2013; Lund et al., 2012; Ströhle and Flath, 2016) or how to adapt them to specific scenarios like electric vehicle charging (De Craemer and Deconinck, 2012; Dauer et al., 2013).

$$
A=\left(\begin{array}{lll}
0 & 0 & 1 \\
0 & 1 & 0 \\
0 & 0 & 1
\end{array}\right), B=\left(\begin{array}{lll}
0 & 0 & 1 \\
0 & 1 & 0 \\
0 & 1 & 0 \\
0 & 1 & 0 \\
0 & 0 & 1
\end{array}\right), \Gamma=\left(\begin{array}{llll}
0 & 0 & 0 & 1 \\
0 & 0 & 1 & 0 \\
0 & 0 & 0 & 1
\end{array}\right), \Delta=\left(\begin{array}{lll}
1 & 0 & 0 \\
1 & 0 & 0 \\
1 & 0 & 0
\end{array}\right)
$$


Again, the morphological approach lends itself to characterise this form of energy service. Here, we assume a market with limit orders on (partial) service completion, i.e., customers specify the maximum price which they are willing to pay for a tendered energy service (fragment). If prices exceed this reservation limit orders will not be executed resulting in unlimited quantity risk. This unlimited quantity risk also corresponds to unlimited delivery time risk. In this market setup there is no interruption risk of an individual market transaction. However, repeated transactions are uncertain to be repeatedly allocated leading to a limited amount of interruption risk.

Price changes are instantaneous after each market clearing with a linear relationship between price and energy. Prices vary over time and apply only to the given marketplace. As noted above, local energy markets have significant infrastructure requirements. Continuous metering and bi-directional communication are necessary to facilitate and monitor market transactions. At the same time customers will most likely be relying on trading agents to pursue their energy trading activity (Vytelingum et al., 2010; Gottwalt et al., 2011). Finally, local marketplaces will need sufficient market liquidity to be successful. Consequently, commoditised energy services with minimal specifications should be traded (Ströhle and Flath, 2016).

\subsection{Prototypical decision support system}

The above formalisation of the morphological box lends itself to facilitating a decision support system for energy service designers. Such a system should guide practitioners by dynamically restricting design choices according to feasibility constraints and thereby improves the focus of the product development process. To illustrate this idea we implemented a prototype for such a decision support system using Microsoft Excel and Visual Basic (left side of Figure 3). Users can interactively select service design elements in the morphological box. Furthermore, they can specify a maximum complexity level for the final energy service. After any decision the system dynamically updates dependencies arising from this decision, updates the current complexity level, and restricts future choices to remain within the complexity "budget." 


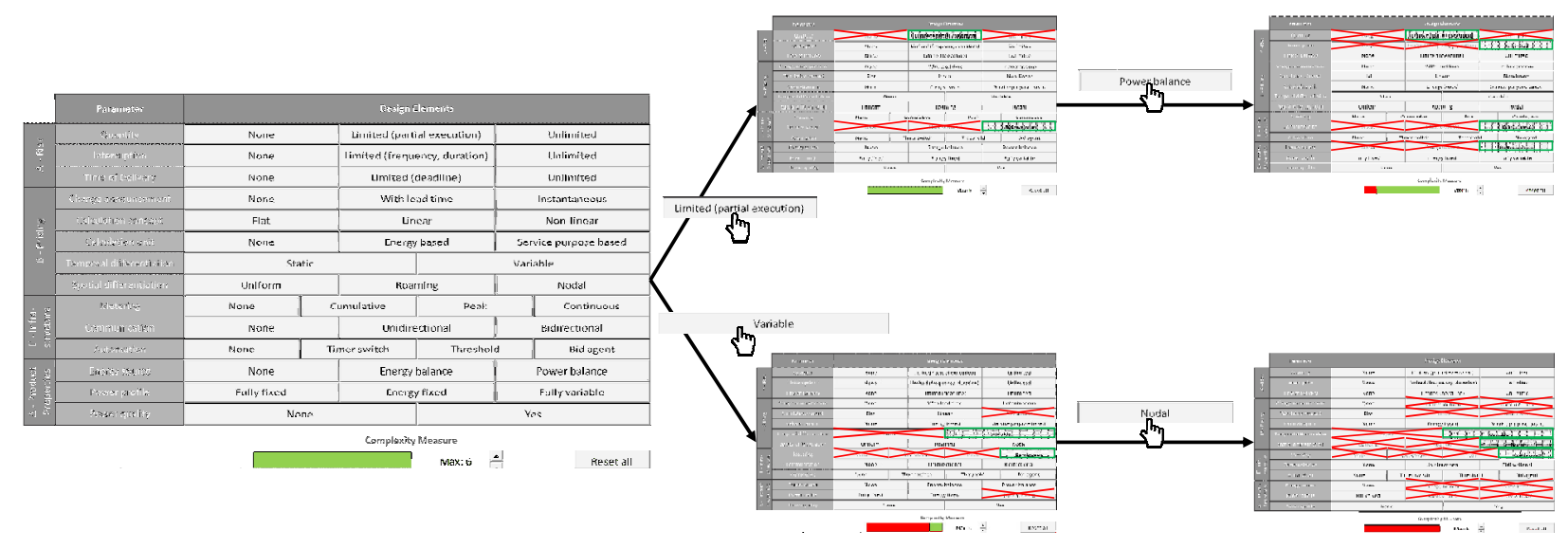

Figure 3: User journey through a prototypical decision support system

The right side of Figure 3 illustrates the system functionality by means of two exemplary user journeys through the tool. The upper branch highlights the effect of interdependencies between design elements: After selecting "limited quantity risk (partial execution)" the system disables the "no communication" and "unidirectional communication" infrastructure design elements and automatically sets the only remaining infrastructure design element "bidirectional communication". Furthermore, after choosing to use a renewable energy source on a "power balance" level, in which case an unlimited interruption risk is inherent (compare Equation 6), the parameter "interruption risk" is fixed to "unlimited". Besides, both choices deplete a minor part of the complexity allowance.

The lower branch demonstrates the effect of the energy service complexity limit. Due to selecting "variable temporal differentiation" of the price, on the one hand, an interdependency occurs (see Equation 2 for "continuous metering"), and on the other hand a "non-linear calculation concept" as well as a "fully variable power profile" becomes indispensable as selecting it would exceed the previously selected maximum complexity level. After selecting "nodal pricing" the maximum complexity level is reached. Therefore, the tool deactivates all other complexity driving design elements. Please note that complexity weights are exemplary in this case.

These user journeys illustrate how decision support systems for energy service design can utilise the morphological box. The presented prototype focuses on reducing the choice 
through constraint and interdependency propagation. A proper implementation in practice should also consider the benefit side of the various design elements (additional profits or cost reductions) to help in determining the most beneficial service offering. To that end, the system should be connected with other corporate information systems (CRM, ERP) and augmented by suitable benefit-assessment-components, e.g., a simulation tool as presented by Gottwalt et al. (2011).

\section{Conclusion and policy implications}

Energy services play a central role to empower the currently mostly passive demand side. This demand side activation is crucial to cope with the risk that arises from a growing share of electricity supply from intermittent renewable energy sources (Papaefthymiou and Dragoon, 2016). Utility companies have started to increase efforts for product development that addresses the new situation in the power system, but there is still a lack of experience and effective methods and tools to support this development (Richter, 2013).

This paper is a first step to set a frame for the structured design of energy services. It proposes a systematic and standardised way to address different product characteristics and their design options, with a particular focus on differentiation options with respect to quality of service attributes. This way, new and innovative combinations of service design options can support activating the flexibility potential of the demand side in a Smart Grid environment and ameliorate some of the supply risk inherent to intermittent generation.

We illustrate pricing options for these (new) energy service products which improves setting the correct incentives for the desired customer behavior and outline infrastructural needs and additional product properties which depend on the specific use case. We then apply the approach by modelling exemplary reference energy service products. Furthermore, we discuss how the morphological approach can be formalised by means of a mathematical programming formulation. Formally describing interdependencies between product design elements increases efficiency by removing incompatible design options. Additionally, we introduce a complexity measure which facilitates assessing potential adoption obstacles for 
end customers. Finally, we illustrate the theoretical concepts by means of a prototypical decision support system for service designers.

\subsection{Policy implications}

The economic viability of cost-based electricity pricing with respect to generation adequacy is lively debated in the face of growing renewable generation shares. So far, the debate has mainly focused on supply side initiatives, e.g., the establishment of capacity markets (Boute, 2012; Browne et al., 2015; Hall, 2014).

However, near zero variable costs also call for a value-based pricing of energy services as a new paradigm. To this end, pricing should be determined by individual customers' valuation for particular service characteristics. Quality-based energy service product differentiation facilitates efficient customer self-selection in response to a change in product characteristics. This enables better participation of numerous flexible loads which jointly can help stabilise the power system (Gottwalt et al., 2016). The micro-transactions arising from these microflexibilities are facilitated by ICT capabilities offered in smart grid environments. The central idea is to (partially) limit supply security by means of active, demand-side risk sharing to stabilise supply security in the long term. Note that such an approach may loosen the current barriers between grids and energy markets in unbundled markets (Greening, 2010).

While it may take some more time until extreme RES penetration scenarios are realised, power markets and infrastructures will have to prepare for these challenges in advance (Mathiesen et al., 2011). Consequently, regulators must pave the way for an environment where a flexible demand side can choose from a richer set of differentiated energy services. This requires establishing a technological infrastructure that enables such a shift. These smart grid platforms must be non-discriminatory and equally accessible for established and new actors to allow for efficient competition. Similarly, some basic energy service with predefined quality characteristics should still be offered for those customers unable or willing to respond to quality differentiated energy service products. To foster this kind of innovation, regulators may need to adopt a more tolerant regulation regime and thus lower the barriers for new market entrants. 
The telecommunication sector developed in an analogous way to the energy sector after liberalisation (Hertzog, 2010; Smith, 2012). Telecommunication companies with differing values were initially founded to account for the customers' different valuations for service quality. Both the range of service quality differentiation options and the robust adaption of the regulatory frame in the telecommunication sector should inspire the energy sector Bourreau and Doan, 2001). One of the ideas that needs further investigation with respect to its implication in the energy service sector is flat rate pricing. Imagine a theoretically unconstrained energy consumption for a particular service while only a fixed, consumption-independent rate is paid. At the same time the quality of supply or in particular the availability of energy from an intermittent source can be a quality differentiation characteristic that only allows flexible consumers (or appliances) to utilise this flat rate energy service. Further work must thus be dedicated to the comparison between the telecommunication and energy sector.

\subsection{Outlook}

We have argued that product differentiation is important to retain economic viability of power systems dominated by renewable energy sources. Our research focused on the conceptual side of service innovation. However, going forward, the economic viability as well as suitable regulatory frameworks have to be evaluated and designed. Therefore, future work should seek to better understand the costs and benefits of individual design options. This will facilitate a proper service design optimisation as envisioned in Section 5.

Introducing interactive decision support systems as illustrated in 5.4 will allow product designers to focus on creative aspects rather than thinking about formal limitations and interdependencies. To help practitioners transfer our ideas into industry applications the prototypical decision support system needs to be expanded and adapted to specific use cases. Ideally, the tool should allow designers to start by developing and parametrising the morphological box and specify interdependencies in a higher level description language.

Another key question is how fast and to what extent service providers can face customers with product differentiation of an originally homogeneous good. Surveys and experimental 
approaches are needed to assess customer acceptance and to develop robust estimates of the complexity scores introduced in Section 5.2. Additionally, customers' risk aversion will influence the acceptance of tariffs designed with our methodology. To formulate promising business cases, practitioners would benefit from a way to take the risk preferences of specific customer groups into account.

\section{References}

Albadi, M. H., El-Saadany, E., 2008. A summary of demand response in electricity markets. Electric Power Systems Research 78 (11), 1989-1996.

Aurich, J. C., Mannweiler, C., Schweitzer, E., 2010. How to design and offer services successfully. CIRP Journal of Manufacturing Science and Technology 2 (3), 136-143.

Barbose, G. L., Goldman, C. A., Neenan, B., Dec 2004. A survey of utility experience with real time pricing. Tech. rep., Lawrence Berkeley National Laboratory, Berkeley.

Bitar, E., Low, S., Dec. 2012. Deadline differentiated pricing of deferrable electric power service. In: 51st IEEE Conference on Decision and Control (CDC). pp. 4991-4997.

Borchers, A. M., Duke, J. M., Parsons, G. R., 2007. Does willingness to pay for green energy differ by source? Energy Policy 35 (6), 3327-3334.

Borenstein, S., 2005. The long-run efficiency of real-time electricity pricing. The Energy Journal 26 (3), 93-116.

Bourreau, M., Doan, P., 2001. Regulation and innovation in the telecommunications industry. Telecommunications Policy 25 (3), 167-184.

Boute, A., 2012. Promoting renewable energy through capacity markets: An analysis of the russian support scheme. Energy Policy 46, 68-77.

Browne, O., Poletti, S., Young, D., 2015. How does market power affect the impact of large scale wind investment in 'energy only' wholesale electricity markets? Energy Policy 87, 17-27.

Chao, H., Wilson, R., 1987. Priority service: Pricing, investment, and market organization. American Economic Review 77 (5), 899-916.

Chen, W., Qiu, L., Varaiya, P., Dec 2015. Duration-deadline jointly differentiated energy services. In: 54th IEEE Conference on Decision and Control (CDC). pp. 7220-7225.

Costello, K., 2004. An observation on real-time pricing: Why practice lags theory. The Electricity Journal 17 (1), 21-25.

Dauer, D., Flath, C. M., Ströhle, P., Weinhardt, C., 2013. Market-based EV charging coordination. In: 
IEEE/WIC/ACM International Joint Conferences on Web Intelligence (WI) and Intelligent Agent Technologies (IAT). Vol. 2. IEEE, pp. 102-107.

Davis, A. E., 2012. Using performance contracting and incentives to accelerate energy efficiency projects. Tech. rep., Johnson Controls, Inc., Johnson Controls White Paper.

Dayton, D., Goldman, C., Pickle, S., Jul 1998. The energy services company (ESCO) industry: Analysis of industry and market trends. Tech. rep., American Council for an Energy-Efficient Economy, Washington, DC (US).

De Craemer, K., Deconinck, G., 2012. Balancing trade-offs in coordinated PHEV charging with continuous market-based control. In: 3rd IEEE PES Innovative Smart Grid Technologies Europe (ISGT Europe). IEEE, pp. 1-8.

Dütschke, E., Paetz, A.-G., 2013. Dynamic electricity pricing - which programs do consumers prefer? Energy Policy 59, 226-234.

Gerpott, T., Paukert, M., 2013. Gestaltung von Tarifen für kommunikationsfähige Messsysteme im Verbund mit zeitvariablen Stromtarifen. Zeitschrift für Energiewirtschaft 37 (2), 83-105.

Giordano, V., Gangale, F., Fulli, G., Jiménez, M. S., Onyeji, I., Colta, A., Papaioannou, I., Mengolini, A., Alecu, C., Ojala, T., et al., 2011. Smart grid projects in Europe: Lessons learned and current developments. JRC Reference Reports, Publications Office of the European Union.

Goett, A. A., Hudson, K., Train, K. E., 2000. Customers' choice among retail energy suppliers: The willingness-to-pay for service attributes. The Energy Journal 21 (4), 1-28.

Goldman, C. A., Hopper, N. C., Osborn, J. G., 2005. Review of US ESCO industry market trends: An empirical analysis of project data. Energy Policy 33 (3), 387-405.

Gottwalt, S., Gärttner, J., Schmeck, H., Weinhardt, C., 2016. Modeling and valuation of residential demand flexibility for renewable energy integration. IEEE Transactions on Smart Grid PP (99), 1-10.

Gottwalt, S., Ketter, W., Block, C., Collins, J., Weinhardt, C., 2011. Demand side management - a simulation of household behavior under variable prices. Energy Policy 39 (12), 8163-8174.

Greening, L. A., 2010. Demand response resources: Who is responsible for implementation in a deregulated market? Energy 35 (4), 1518-1525.

Hall, S., 2014. EU electricity market capacity mechanisms unavoidable. Website: http://www. platts.com/news-feature/2014/electricpower/eu-electricity-capacity-mechanisms/index, accessed 04.08.2016.

Hammerstrom, D., Ambrosio, R., Brous, J., Carlon, T., Chassin, D., DeSteese, J., Guttromson, R., Horst, G., Järvegren, O., Kajfasz, R., et al., 2007. Pacific northwest gridwise testbed demonstration projects. Tech. rep., Pacific Northwest National Laboratory, Richland.

Hansla, A., Gamble, A., Juliusson, A., Gärling, T., 2008. Psychological determinants of attitude towards 
and willingness to pay for green electricity. Energy Policy 36 (2), 768-774.

Hertzog, C., 2010. Telecom industry lessons for electric utilities part 2. Website: http: //www.smartgridlibrary.com/2010/01/25/telecom-industry-lessons-for-electric-utilitiespart-2/, accessed 04.08.2016.

Hill, T., 1977. On Goods and Services. Review of Income and Wealth 23 (4), 315-338.

Homburg, C., Totzek, D., Krämer, M., 2014. How price complexity takes its toll: The neglected role of a simplicity bias and fairness in price evaluations. Journal of Business Research 67 (6), 1114-1122.

IEA, 2014. The power of transformation: Wind, sun and the economics of flexible power systems. Tech. rep., International Energy Agency.

Jazayeri, P., Schellenberg, A., Rosehart, W. D., Doudna, J., Widergren, S., Lawrence, D., Mickey, J., Jones, S., Aug 2005. A survey of load control programs for price and system stability. IEEE Transactions on Power Systems 20 (3), 1504-1509.

Kaenzig, J., Heinzle, S. L., Wüstenhagen, R., 2013. Whatever the customer wants, the customer gets? Exploring the gap between consumer preferences and default electricity products in Germany. Energy Policy 53, 311-322.

Kenyon, C., Cheliotis, G., 2001. Stochastic models for telecom commodity prices. Computer Networks 36 (56), 533-555.

Ketter, W., Collins, J., Reddy, P., 2013. Power TAC: A competitive economic simulation of the smart grid. Energy Economics 39, 262-270.

Kley, F., Lerch, C., Dallinger, D., 2011. New business models for electric cars - a holistic approach. Energy Policy 39 (6), 3392-3403.

Kloubert, T., 2000. Energiemarketing - ein dienstleistungsorientierter Ansatz. Zeitschrift für Energiewirtschaft 24 (4), 225-236.

Lay, G., Schroeter, M., Biege, S., 2009. Service-based business concepts: A typology for business-to-business markets. European Management Journal 27 (6), 442-455.

Layer, P., Feurer, S., Jochem, P., 2016. Pricing for the Energiewende. In: American Marketing Association Winter Academic Conference 2016 Proceedings, Las Vegas, USA (Feb 26-28).

LeVine, S., Zolfaghari, A., Polak, J., 2014. Carsharing: Evolution, challenges and opportunities. Tech. rep., Centre for Transport Studies, Imperial College London.

Lund, H., Andersen, A. N., Østergaard, P. A., Mathiesen, B. V., Connolly, D., 2012. From electricity smart grids to smart energy systems - a market operation based approach and understanding. Energy 42 (1), $96-102$.

Mathiesen, B. V., Lund, H., Karlsson, K., 2011. 100\% renewable energy systems, climate mitigation and economic growth. Applied Energy 88 (2), 488-501. 
Minnesota Power, 2012. Residential rates. Website: http://www.mnpower.com/CustomerService/ ResidentialRates, accessed 09.03.2016.

Nayyar, A., Negrete-Pincetic, M., Poolla, K., Varaiya, P., Dec 2014. Duration-differentiated energy services with a continuum of loads. In: 53rd IEEE Conference on Decision and Control (CDC). pp. 1714-1719.

Oren, S. S., Jan 2013. A historical perspective and business model for load response aggregation based on priority service. In: 46th Hawaii International Conference on System Sciences (HICSS). pp. 2206-2214.

Papaefthymiou, G., Dragoon, K., 2016. Towards 100\% renewable energy systems: Uncapping power system flexibility. Energy Policy 92, 69-82.

Parasuraman, A., Zeithaml, V. A., Berry, L. L., 1988. SERVQUAL. Journal of Retailing 64 (1), $12-40$.

Parasuraman, A., Zeithaml, V. A., Malhotra, A., 2005. ES-QUAL a multiple-item scale for assessing electronic service quality. Journal of Service Research 7 (3), 213-233.

Petersen, M. K., Edlund, K., Hansen, L. H., Bendtsen, J., Stoustrup, J., June 2013. A taxonomy for modeling flexibility and a computationally efficient algorithm for dispatch in smart grids. In: American Control Conference. pp. 1150-1156.

Richter, M., 2013. Business model innovation for sustainable energy: German utilities and renewable energy. Energy Policy 62, 1226-1237.

Rinaldi, S. M., 2004. Modeling and simulating critical infrastructures and their interdependencies. In: Proceedings of the 37th Annual Hawaii International Conference on System Sciences.

Roe, B., Teisl, M. F., Levy, A., Russell, M., 2001. US consumers willingness to pay for green electricity. Energy Policy 29 (11), 917-925.

Rosmanith, C., Hackel, S., Pichler, E., Hoehne, U., Molnar, P., Lackner, M., Kapfer, M., Predota, A., 2007. Energy services as an integral part of the distribution. Tech. rep., Federal Ministry for Transport, Innovation and Technology, Austria.

Salah, F., Flath, C. M., 2016. Deadline differentiated pricing in practice: marketing EV charging in car parks. Computer Science - Research and Development 31 (1), 33-40.

Satchwell, A., 2010. A survey of the U.S. ESCO industry: Market growth and development from 2008 to 2011. Tech. rep., Lawrence Berkeley National Laboratory, Berkeley.

Schön, C., 2010. On the optimal product line selection problem with price discrimination. Management Science 56 (5), 896-902.

Schweppe, F., Daryanian, B., Tabors, R., 1989. Algorithms for a spot price responding residential load controller. IEEE Transactions on Power Systems 4 (2), $507-516$.

Schweppe, F. C., 1988. Management of a spot price based energy marketplace. Energy policy 16 (4), 359-368.

Schweppe, F. C., Caramanis, M. C., Tabors, R. D., Bohn, R. E., 1988. Spot Pricing of Electricity. Power Electronics and Power Systems. Springer US. 
Schweppe, F. C., Tabors, R. D., Kirtley, J. L., 1981. Homeostatic control: The utility/customer marketplace for electric power. Tech. rep., Massachusetts Institute of Technology, Energy Laboratory.

Smith, R., 2012. What can utilities learn from telecoms as it moves to smart met. Website: http://www.telcoprofessionals.com/blogs/6038/945/what-can-utilities-learn-fromtelecoms-as-it-moves-to-smart-met, accessed 04.08.2016.

Sorrell, S., 2007. The economics of energy service contracts. Energy Policy 35 (1), 507-521.

Ströhle, P., Flath, C. M., 2016. Local matching of flexible load in smart grids. European Journal of Operational Research 253 (3), 811-824.

Stryja, C., Fromm, H., Ried, S., Jochem, P., Fichtner, W., 2015. On the necessity and nature of e-mobility services - towards a service description framework. In: Nova, H., Dragoicea, M. (Eds.), Exploring Services Science. Vol. 201 of Lecture Notes in Business Information Processing. Springer International Publishing, pp. 109-122.

Tan, C.-W., Varaiya, P., 1993. Interruptible electric power service contracts. Journal of Economic Dynamics and Control 17 (3), 495-517.

Tirole, J., 1988. The theory of industrial organization. MIT press.

Varian, H. R., 1989. Price discrimination. In: Handbook of Industrial Organization. Vol. 1. Elsevier, pp. $597-654$.

Vickrey, W., 1971. Responsive pricing of public utility services. The Bell Journal of Economics and Management Science 2 (1), 337-346.

Vine, E., 2005. An international survey of the energy service company (ESCO) industry. Energy Policy $33(5), 691-704$.

Vine, E., Nakagami, H., Murakoshi, C., 1999. The evolution of the US energy service company (ESCO) industry: from ESCO to Super ESCO. Energy 24 (6), 479-492.

Vytelingum, P., Ramchurn, S. D., Voice, T. D., Rogers, A., Jennings, N. R., 2010. Trading agents for the smart electricity grid. In: Proceedings of the 9th International Conference on Autonomous Agents and Multiagent Systems. International Foundation for Autonomous Agents and Multiagent Systems, pp. 897-904.

Weinhardt, C., Holtmann, C., Neumann, D., 2003. Market-engineering. Wirtschaftsinformatik 45 (6), 635640.

Woo, C.-K., Sreedharan, P., Hargreaves, J., Kahrl, F., Wang, J., Horowitz, I., 2014. A review of electricity product differentiation. Applied Energy 114 (0), 262-272.

Yoo, S.-H., Kwak, S.-Y., 2009. Willingness to pay for green electricity in Korea: A contingent valuation study. Energy Policy 37 (12), 5408-5416.

Zwicky, F., 1948. The morphological method of analysis and construction. CalTec. 
Zwicky, F., 1967. The morphological approach to discovery, invention, research and construction. In: Zwicky, F., Wilson, A. G. (Eds.), New Methods of Thought and Procedure. Springer Berlin Heidelberg, pp. 273297. 